Article

\title{
Effects of Chitosan-Based Coatings Enriched with Cinnamaldehyde on Mandarin Fruit cv. Ponkan during Room-Temperature Storage
}

\author{
Yang Gao ${ }^{1}$, Chaonan Kan ${ }^{1}$, Ming Chen ${ }^{1}$, Chuying Chen ${ }^{1}$, Yuhuan Chen ${ }^{1}$, Yongqi Fu ${ }^{1}$, \\ Chunpeng Wan ${ }^{1, *}$ and Jinyin Chen ${ }^{1,2, *}$ \\ 1 Jiangxi Key Laboratory for Postharvest Technology and Nondestructive Testing of Fruits \& Vegetables, \\ Collaborative Innovation Center of Post-Harvest Key Technology and Quality Safety of Fruits and \\ Vegetables, College of Agronomy, Jiangxi Agricultural University, Nanchang 330045, China; \\ gyyichuan@163.com (Y.G.); KCn19921012@163.com (C.K.); chenming@jxau.edu.cn (M.C.); \\ ccy0728@126.com (C.C.); chenyh5207@126.com (Y.C.); fuyongqi@126.com (Y.F.) \\ 2 Pingxiang University, Pingxiang 337055, China \\ * Correspondence: chunpengwan@jxau.edu.cn (C.W.); jinyinchen@126.com (J.C.); \\ Tel.: +86-791-8381-3058 (J.C.)
}

Received: 24 August 2018; Accepted: 20 October 2018; Published: 22 October 2018

\begin{abstract}
The current work aimed to evaluate the efficacy of four coating formulations-chitosan coating $(\mathrm{CH}), 0.5 \%$ cinnamaldehyde + chitosan $(0.5 \% \mathrm{CI}-\mathrm{CH}), 1.0 \%$ cinnamaldehyde + chitosan $(1.0 \%$ $\mathrm{CI}-\mathrm{CH})$, and $1.5 \%$ cinnamaldehyde + chitosan $(1.5 \% \mathrm{CI}-\mathrm{CH})$ - on fresh mandarin fruit cv. Ponkan quality maintenance (weight loss, decay rate, total soluble solids, titratable acidity, vitamin C, color index, malondialdehyde, and antioxidant activity) over 100 days of storage at $20{ }^{\circ} \mathrm{C}$. Compared to the control, chitosan treatment effectively reduced the decay and weight loss rates of mandarin fruit $\mathrm{cv}$. Ponkan during storage at room temperature, delayed the decline of nutritional quality in fruits, increased the antioxidant capacity, and inhibited the accumulation of malondialdehyde (MDA). In comparison to chitosan coating, $1.5 \% \mathrm{CI}-\mathrm{CH}$ did not improve the fruit storage effect, but inhibited the normal color change of fruits and increased the accumulation of MDA. Both $0.5 \% \mathrm{CI}-\mathrm{CH}$ and $1.0 \% \mathrm{CI}-\mathrm{CH}$ effectively reduced the rate of fruit decay, improved the quality of fruits after harvest, and delayed fruit aging. Our study suggests that $0.5 \% \mathrm{CI}-\mathrm{CH}$ and $1.0 \%$ $\mathrm{CI}-\mathrm{CH}$ might be good formulations for maintaining the quality of mandarin fruit cv. Ponkan during room-temperature storage.
\end{abstract}

Keywords: chitosan; coating; cinnamaldehyde; fruit; room temperature

\section{Introduction}

Citrus is the most important commodity fruit in the world and the most widely cultivated fruit tree type in the subtropics of China. The genus citrus includes orange, grapefruit, kumquat, lemon, and many others, including various varieties in each species [1]. Mandarin fruit cv. Ponkan (Citrus reticulata Blanco cv. Ponkan) is a widely cultivated citrus variety in southern China. Its fruit matures in mid-November to late December. The skin of mature Ponkan is orange and easy to peel, and the pulp is crisp and juicy, with a strong flavor [2]. In actual production, based on cost and technical constraints, the fruit growers usually store the picked Ponkan fruits at room temperature. However, Ponkan has a thin skin, and the quality of the fruit during storage at room temperature is highly prone to deterioration and decay over time [3]. Improving the storage performance and reducing fruit decay during storage and transportation are major problems for the citrus industry. At present, the postharvest preservation technology for citrus mainly includes low-temperature storage, coating, 
postharvest heating, and chemical fungicidal treatment [4-6]. Nowadays, most of the chemicals used for postharvest treatment are fungicidal, which do not decompose easily and remain on the surface of the fruits; as a result, they can endanger the environment as well as consumer health $[7,8]$.

Cinnamaldehyde is a well-known food flavor additive that has been approved by the food and drug administrations of China and the United States [9] as a safe and effective active antimicrobial substance in food packaging $[10,11]$. The pathogens that cause citrus diseases include the species: Penicillium italicum, Penicillium digitatum, Geotrichum candidum, Colletotrichum gloeosporioides, Alternaria spp., and Phytophthora spp. Cinnamaldehyde shows promising antifungal activities against these six citrus pathogens. To further understand the antifungal mechanism of cinnamaldehyde, differential metabolites of control and cinnamaldehyde-treated Penicillium italicum were identified by 1H-NMR metabolomics analysis [12]. Previously, we reported that the minimum inhibitory concentration (MIC) and minimum fungicidal concentration (MFC) of cinnamaldehyde solution against $P$. italicum were $0.025 \mathrm{mg} / \mathrm{mL}$ and $0.1 \mathrm{mg} / \mathrm{mL}$, respectively. Cinnamaldehyde effectively inhibited the spore germination of $P$. italicum, impeded the growth of the mycelium, and destroyed the cell membrane, so that the energy metabolism pathway of the mycelium was slowed, thus inhibiting the normal growth and development of P. italicum [13]. Although essential oils have been proven to be good antifungal agents, their application for reducing decay development and maintaining fruit quality is frequently limited because of their high volatility, strong flavor, and various other disadvantages. Incorporating essential oils into edible coatings is an effective method to slow down the decay process, as well as to control fruit fungal diseases by reducing the diffusion process and maintaining high concentrations of active molecules on fruit surfaces [14-16].

Chitosan is a nontoxic, odorless, and biodegradable polysaccharide with good film formation and broad-spectrum antimicrobial properties. Moreover, it can be used as a preservative for the postharvest preservation of fruits and vegetables [17-19]. However, the antimicrobial effect of chitosan can be influenced by modulating acetylation, molecular weight, and external environment [20]. Many studies have reported adding antimicrobial ingredients to chitosan biofilms, and enhanced antimicrobial effects have been observed [21,22]. It has been reported that cinnamaldehyde and chitosan can be compounded into an antimicrobial film. For example, peppers coated with chitosan-cinnamaldehyde oil maintain good sensory quality, and this is an effective way to improve the quality of sweet peppers in storage [23].

Fruit quality assessment includes many indicators. Weight loss and decay rate are important parameters used to evaluate fruit storage tolerance. The contents of sugar, acid, and vitamin C $(\mathrm{Vc})$ are important nutritional quality indices of fruit, and will affect the taste of fruit. Peel color is an important appearance index of fruit, and its quality will affect consumers' purchasing intention [24]. Malondialdehyde (MDA) is one of the main products of membrane lipid peroxidation, and it is toxic to the cells. The higher the content of MDA, the greater the degree of damage to cells. Therefore, MDA content is also an important indicator for evaluating fruit quality [25]. The senescence of fruit is related to the activity of antioxidant enzymes such as catalase (CAT), peroxidase (POD), and superoxide dismutase (SOD), which are the most important for scavenging reactive oxygen species. They can delay aging caused by oxidative damage during fruit storage [26].

In order to overcome the main limitations of storage at room temperature of mandarin fruit cv. Ponkan, this study determined the effects of different concentrations of cinnamaldehyde-chitosan coating on the color and quality of Ponkan fruits during storage at room temperature $\left(20^{\circ} \mathrm{C}\right)$. This could provide a theoretical basis for the application of cinnamaldehyde-chitosan coating on citrus fruits.

\section{Materials and Methods}

\subsection{Fruit Materials}

Mandarin fruit cv. Ponkan (Citrus reticulata Blanco cv. Ponkan) were harvested from Jing'an, Yichun, Jiangxi, China. The fruits were uniform in size, maturity, color, and shape, and free of any 
pests or damage/spots. After harvest, the fruits were immediately delivered to the Laboratory for Postharvest Technology and Nondestructive Testing of Fruits and Vegetables, Jiangxi Agriculture University (Nanchang, China).

\subsection{Preparation of Coating}

Chitosan coating $(\mathrm{CH}), 1.5 \%(\mathrm{w} / \mathrm{v})$ : $600 \mathrm{~g}$ food-grade chitosan (Zhejiang Yi Meng Biotechnology Co., Ltd., Hangzhou, China) was added to $40 \mathrm{~L}$ aqueous solution (containing 1.0\% acetic acid, $2.0 \%$ Tween 80 , and $0.35 \%$ sodium chloride) and stirred well at room temperature to dissolve the chitosan.

Cinnamaldehyde-chitosan coating, $0.5 \%(\mathrm{w} / \mathrm{v})(0.5 \% \mathrm{CI}-\mathrm{CH}): 50 \mathrm{~g}$ cinnamaldehyde (Aladdin Industrial Corporation, Shanghai, China) was added to $10 \mathrm{~L}$ of the prepared $1.5 \%$ chitosan coating, stirred at room temperature, and mixed well.

Cinnamaldehyde-chitosan coating, 1.0\% (w/v) (1.0\% CI-CH): $100 \mathrm{~g}$ cinnamaldehyde (Aladdin Industrial Corporation, Shanghai, China) was added to $10 \mathrm{~L}$ of the prepared $1.5 \%$ chitosan coating, stirred at room temperature, and mixed well.

Cinnamaldehyde-chitosan coating, $1.5 \%$ (w/v) $(1.5 \% \mathrm{CI}-\mathrm{CH}): 150 \mathrm{~g}$ cinnamaldehyde (Aladdin Industrial Corporation, Shanghai, China) was added to $10 \mathrm{~L}$ of the prepared $1.5 \%$ chitosan coating, stirred at room temperature, and mixed well.

\subsection{Fruit Treatments}

All fruits were washed with water and air-dried. The washed fruits were soaked in water (control), $\mathrm{CH}, 0.5 \% \mathrm{CI}-\mathrm{CH}, 1.0 \% \mathrm{CI}-\mathrm{CH}$, or $1.5 \% \mathrm{CI}-\mathrm{CH}$ for $30 \mathrm{~s}$, then air-dried. Each treatment was composed of 900 fruits. The fruits were packed in perforated low-density polyethylene bags (diameter $=0.04 \mathrm{~mm}$ ) and stored in a fruit temperature-controlled cabinet (90-95\% relative humidity and $20 \pm 1{ }^{\circ} \mathrm{C}$ ). Samples were taken on days $0,20,40,60,80$, and 100 , and the relevant indicators were determined.

\subsection{Quality Determinations}

\subsubsection{Weight Loss}

Weight loss was determined with samples of 20 fruits per treatment. The fruits from each treatment were weighed at $0,20,40,60,80$, and 100 days of storage. The weight loss was calculated as follows:

$$
\text { weight loss }=\frac{\text { initial weight }- \text { weighing weight }}{\text { initial weight }} \times 100 \%
$$

\subsubsection{Decay Rate}

To determine the rate of decay, 300 fruits were processed and divided into three replicates. The number of rotting fruits was counted every 20 days. The following equation was used to calculate the decay rate of fruits:

$$
\text { decay rate }=\frac{\text { rotting fruits }}{\text { total fruits }} \times 100 \%
$$

\subsubsection{Total Soluble Solids, Titratable Acidity, and Vitamin C}

A homogeneous sample of 10 fruits was prepared for each treatment to measure the content of total soluble solids (TSS), titratable acidity (TA), and vitamin C (Vc). TSS content was measured with an RA-250WE digital brix meter (Kyoto, Tokyo, Japan). TA content was determined by the acid-base titration method. Vc content was determined by 2-6-dichloroindophenol titration [27].

\subsubsection{Color Index}

Ten fruits from each treatment time were used for the determination of surface color change. This was carried out with a chromameter (CR-400, Konica Minolta, Osaka, Japan) at four evenly distributed 
equatorial sites of each fruit [28]. Citrus color index was calculated according to methods reported before [29].

$$
C C I=1000 \times a * /(L * \times b *)
$$

\subsubsection{Content of Malondialdehyde of Fruit Peel}

MDA content was determined by the thiobarbituric acid colorimetric method [30]. First, $1 \mathrm{~g}$ of the sample was weighed, and after thorough grinding, $8 \mathrm{~mL}$ of $10 \%$ trichloroacetic acid was added and centrifuged at $10,000 \times g$ for $15 \mathrm{~min}$. Then $2 \mathrm{~mL}$ of the supernatant was placed into the test tube, $2 \mathrm{~mL}$ of $0.6 \%$ thiobarbituric acid was added, water was boiled for $15 \mathrm{~min}$, the mixture was rapidly cooled and centrifuged, and the absorbance of the supernatant was measured at 450, 532, and $600 \mathrm{~nm}$ wavelengths.

\subsubsection{Enzyme Measurements of Fruit Peel}

Activities of catalase (CAT; EC 1.1.11.6), superoxide dismutase (SOD; EC 1.15.1.1), peroxidase (POD; EC 1.11.1.7), and polyphenol oxidase (PPO; EC 1.10.3.2) were assayed according to Ali [17] as described by Hirai [31]. The enzyme solution was prepared as follows: $1.0 \mathrm{~g}$ of peel was placed in a precooled mortar, $8 \mathrm{~mL}$ of precooled $0.5 \mathrm{mmol} / \mathrm{L}$ phosphate buffer $(\mathrm{pH} 7.8)$ was added, then the mixture was ground into a slurry on an ice bath and transferred to a centrifuge tube. After centrifugation at $10,000 \times g$ for $20 \mathrm{~min}$ at $4{ }^{\circ} \mathrm{C}$, the supernatant served as the enzyme solution.

CAT activity was determined by the ultraviolet absorption method. The reaction mixture consisted of $1.0 \mathrm{~mL}$ of $0.3 \%$ hydrogen peroxide, $1.9 \mathrm{~mL}$ of buffered substrate $(0.05 \mathrm{M}$ sodium phosphate buffer, $\mathrm{pH} 7.0$ ), and $0.1 \mathrm{~mL}$ of the enzyme solution. Enzyme activity was measured at $240 \mathrm{~nm}$ by using a spectrophotometer (UV-2600, Shimadzu, Kyoto, Japan). The increase in absorbance was recorded every $30 \mathrm{~s}$ for $3 \mathrm{~min}$. One unit of POD activity was defined as an increase in absorbance at $0.001 / \mathrm{min}$.

POD activity was determined by the guaiacol method. The reaction mixture consisted of $0.1 \mathrm{~mL}$ of $0.4 \%$ guaiacol, $0.1 \mathrm{~mL}$ of $0.46 \% \mathrm{H}_{2} \mathrm{O}_{2}, 2 \mathrm{~mL}$ of buffered substrate $(0.05 \mathrm{M}$ sodium phosphate buffer, $\mathrm{pH} 7.0$ ), and $1 \mathrm{~mL}$ of the enzyme solution. Enzyme activity was measured at $470 \mathrm{~nm}$ by using a spectrophotometer (UV-2600, Shimadzu, Kyoto, Japan). The increase in absorbance was recorded every $30 \mathrm{~s}$ for $3 \mathrm{~min}$. One unit of POD activity was defined as an increase in absorbance at $0.001 / \mathrm{min}$.

SOD activity was determined by the nitroblue tetrazolium photoreduction method. First, $0.1 \mathrm{~mL}$ of the enzyme solution was added to $5 \mathrm{~mL}$ of the reaction medium (containing $15 \mathrm{mmol} / \mathrm{L}$ Met, $65 \mu \mathrm{mol} / \mathrm{L}$ NBT, $2.0 \mu \mathrm{mol} / \mathrm{L}$ riboflavin, and $0.1 \mathrm{mmol} / \mathrm{L}$ EDTA, prepared with $50 \mathrm{mmol} / \mathrm{L} \mathrm{pH} 7.8$ phosphate buffer). After 15 min of illumination (4000 lx), the absorbance was measured immediately at $240 \mathrm{~nm}$ using a spectrophotometer (UV-VIS 04834, Shimadzu, Kyoto, Japan), and the buffer solution was used as a blank. The enzyme activity was determined by inhibiting the NBT photochemical reaction by $50 \%$ as 1 enzyme activity unit (U).

\subsection{Data Analysis}

The experiment was designed in a completely randomized manner by measuring three independent duplicate datasets, and all data are expressed as means + standard deviation (SD). One-way ANOVA was performed using Duncan's multivariate trial in SPSS Statistical 17 software (SPSS, Chicago, IL, USA). A value of $p<0.05$ was considered to be statistically significant.

\section{Results and Discussion}

\subsection{Weight Loss}

The weight loss of the control and coated samples during storage were determined (Figure 1).

During storage at room temperature, the weight loss rate of each sample gradually increased and reached the maximum at 100 days of storage (Figure 1). This could be due to a water vapor pressure gradient in different compartments of the fruit cell tissue, through which moisture was transferred from the fruit into the immediate environment [32]. Compared with the controls, the weight loss rate of 
the coated samples slowed down at the late storage stage. At 100 days of storage, the weight loss rate of the coated samples was significantly lower than that of the control fruit $(p<0.05)$, and they exhibited weight reductions of up to $12.46-33.71 \%$. These results are in agreement with previous studies, which reported that weight loss in navel orange coated with $1.5 \%$ chitosan was only $46.52 \%$ of the control [33]. This behavior can be explained by the fact that chitosan forms a film on the surface of the fruit, which hinders the exchange of water vapor, thereby reducing water loss through transpiration [34].

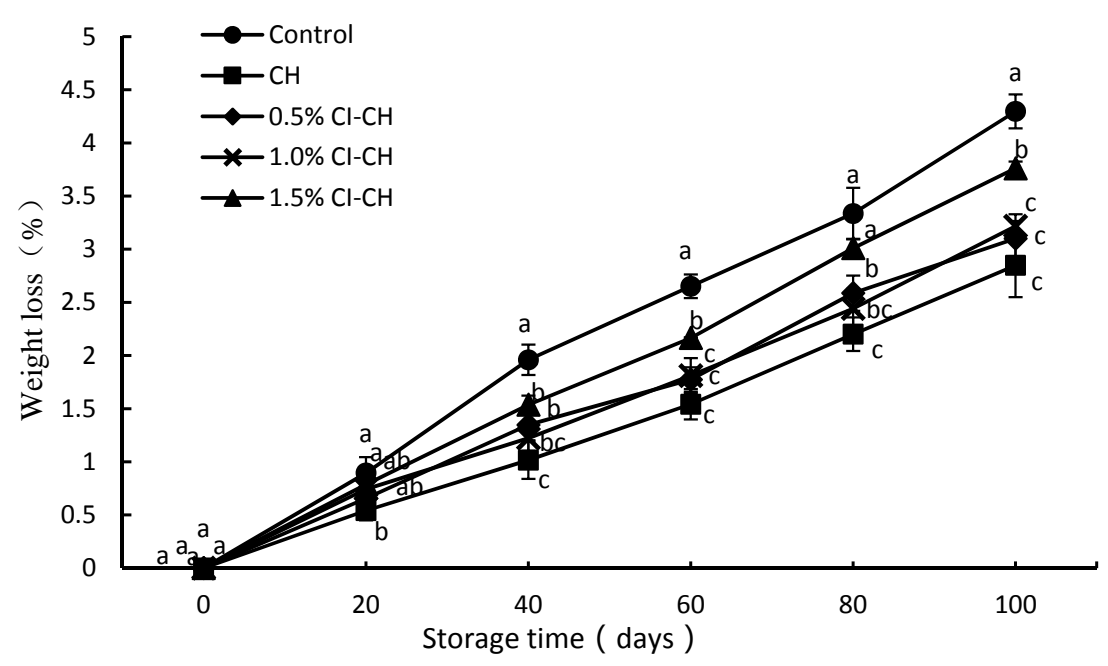

Figure 1. Effect of cinnamaldehyde composite coating on weight loss of mandarin fruits cv. Ponkan during room-temperature storage. Each value represents the mean $\pm \mathrm{SD}$ of three replicates; those marked with lowercase letters are significantly different at $p \leq 0.05$ according to Duncan's multiple range test.

\subsection{Decay Rate}

During storage at room temperature, the decay rate of citrus fruit gradually increased with storage time. The control fruits showed rot on the 20th day of storage, and the decay rate reached $60.67 \%$ on day 100 of storage. The main postharvest diseases of citrus fruit decay were blue mold, green mold, and sour rot, which were caused by the infection of Penicillium italicum, Penicillium digitatum, and Oospora citriaurantii, respectively. Compared with the control, the single chitosan coating $(\mathrm{CH})$ significantly reduced the fruit decay rate at the end of storage (Figure 2), mainly because of the antifungal properties of chitosan. Due to its antimicrobial properties, chitosan has been widely used in antimicrobial films to provide edible protective coatings for foods by dipping and spraying [10]. Citrus fruits treated with postharvest chitosan had increased resistance to anthracnose, and the incidence of lesions was directly reduced [35]. The fruit was treated with $0.5 \%$ and $1.0 \%$ cinnamaldehyde in the chitosan coating, and the rot rate was significantly reduced $(p<0.05)$. At day 100 of storage, the fruit decay rates were only $30.10 \%$ and $22.82 \%$ of the control decay rate, which was significantly lower than that of the chitosan coating $(p<0.05)$. Cinnamaldehyde showed the ability to control postharvest pathogens of citrus fruit [15]. Chitosan reacts with cinnamaldehyde, forming imine linkages; moreover, cinnamaldehyde crosslinks the chitosan chains [36,37], so the antifungal activity of the composite film was increased, the disease resistance of the fruit was increased, and the fruit rot incidence rate was reduced [20]. The decay rate of fruits treated with $1.5 \% \mathrm{CI}-\mathrm{CH}$ was significantly lower than that of the control but there was no significant difference compared with chitosan-treated fruits $(p<0.05)$. This may be due to the excessive concentration of cinnamaldehyde, increased cracks and roughness on the surface of the composite film, decreased toughness, and the occurrence of voids [38], which may have a certain effect on fruit rot. 


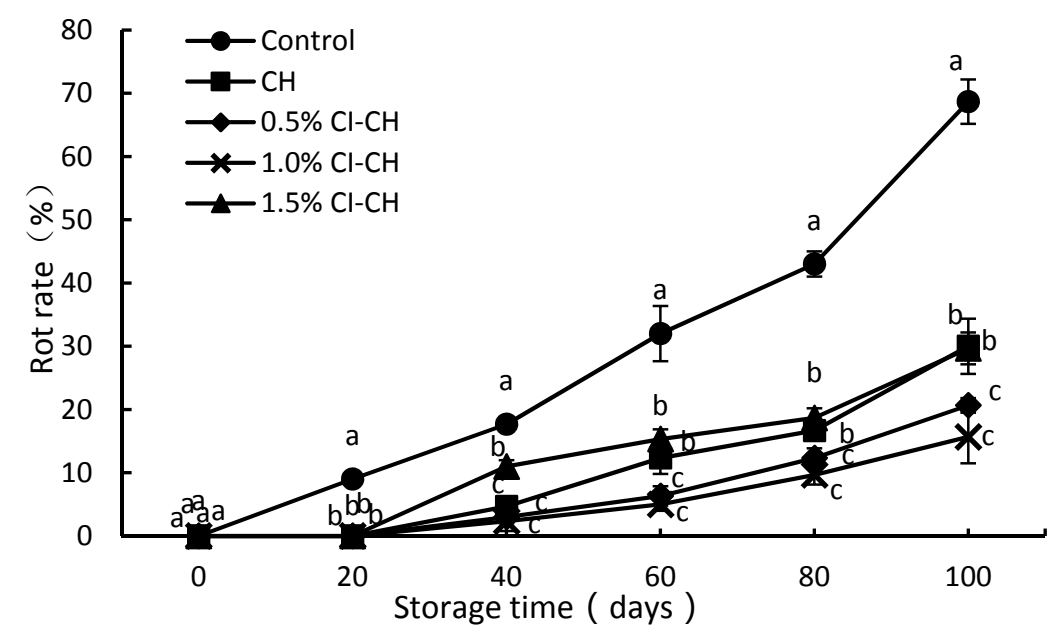

Figure 2. Effect of cinnamaldehyde composite coating on the decay rate of mandarin fruits cv. Ponkan during room-temperature storage. Each value represents the mean $\pm \mathrm{SD}$ of three replicates; those marked with lowercase letters are significantly different at $p \leq 0.05$ according to Duncan's multiple range test.

\subsection{Total Soluble Solids, Titratable Acidity, and Vitamin C}

The effects of postharvest treatment on the main TSS, TA, and Vc contents of Ponkan fruit were different during room-temperature storage (Figure 3). The TSS content increased initially but later decreased (Figure 3a). The TSS content of the control fruit reached the highest value $(12.47 \%)$ on day 40 and then decreased. The TSS content at the end of storage was only $11.00 \%$. Coating treatment prolonged the appearance of TSS peaks and delayed the decline of TSS content in the later storage period. At the end of storage, the TSS content of all coated fruits was significantly higher than that of the control. This could be explained by the coating changing the composition of the gas within the fruit (oxygen and carbon dioxide), thereby affecting the respiratory metabolism and delaying the formation and degradation of carbohydrates in the fruit [39].

During storage at room temperature, the TA content of Ponkan fruit gradually decreased (Figure 3b), which was consistent with the changes observed on other citrus fruit, such as Newhall navel orange [40] and Nanfeng mandarin [41]. Their organic acids and TA content were observed to decrease during storage. Compared with the control, $\mathrm{CH}$ and $\mathrm{CI}-\mathrm{CH}$ effectively delayed the decrease of TA content in Ponkan fruit, so that the TA contents in coated samples were significantly higher than that in the control at the end of storage. This may be because the coating inhibited the enzyme activity related to organic acid metabolism in citrus fruit, resulting in a decrease in organic acid content. Chitosan coating inhibited the expression of genes that regulate malate metabolism enzyme activity, and delayed the degradation of acid in pear fruit during the storage period [42].

The Vc content of Ponkan fruit gradually increased in the early storage period, and decreased in the middle and late storage periods (Figure 3c). Each coating treatment delayed the degradation of Vc content of the fruit. On the 100th day of storage, the Vc content of the control group was 26.01 $\mathrm{mg} \cdot \mathrm{kg}^{-1}$, and of the fruit treated with $\mathrm{CH}$ and $0.5 \%, 1.0 \%$, and $1.5 \% \mathrm{CI}-\mathrm{CH}$ was $8.66 \%, 13.85 \%, 14.72 \%$, and $3.46 \%$, respectively, higher than that of the control. Except for $1.5 \% \mathrm{CI}-\mathrm{CH}$, the Vc content of other coated fruits was significantly higher than that of the control $(p<0.05)$, which was consistent with the changes observed in navel orange [33].

These results indicate that cinnamaldehyde-chitosan coating helped to delay the decline of nutritive quality of Ponkan fruit. 

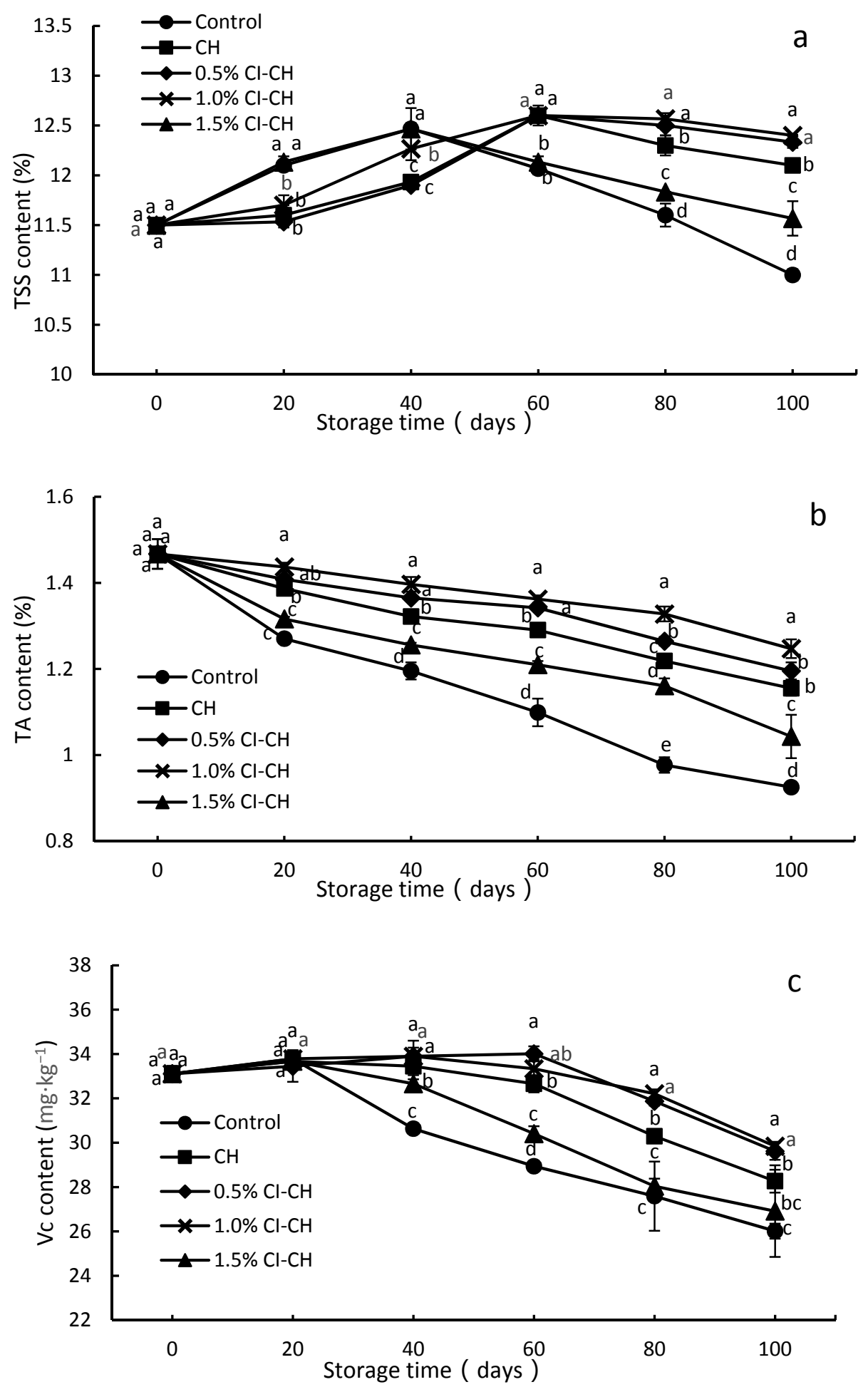

Figure 3. Effect of cinnamaldehyde composite coating on (a) total soluble solids (TSS), (b) titratable ability (TA), and (c) vitamin C (Vc) of mandarin fruits cv. Ponkan during room-temperature storage. Each value represents the mean $\pm \mathrm{SD}$ of three replicates; those marked with different lowercase letters are significantly different at $p \leq 0.05$ according to Duncan's multiple range test.

\subsection{Color Index}

Changes of the color index $(\mathrm{CCI})$ of Ponkan fruit peel during room-temperature storage were determined (Figure 4). 
Ponkan is a late-ripening citrus variety. Its peel coloration time is late and the degree of coloration is relatively weak. In order to avoid low-temperature damage, the fruits were harvested when the pulp had reached maturity and the skin was not partially colored [29]. When storage began, the fruit's CCI value was lower than 1 (Figure 4). With longer storage time, the color of the peel turned from green to pale yellow, and the CCI values gradually increased. This is due to the decrease in chlorophyll content in the citrus peel and the increase in carotenoid content during storage at room temperature [43]. There was no significant difference between the color difference of the control fruit and $\mathrm{CH}$ and $0.5 \%$ or $1.0 \%$ $\mathrm{CI}-\mathrm{CH}$ fruit. However, the $\mathrm{CCI}$ value of the $1.5 \% \mathrm{CI}-\mathrm{CH}$ fruit was significantly lower than that of the control during storage $(p<0.05)$. This indicated that the chitosan coating and the low concentration of cinnamaldehyde in the coating did not affect the color change of the citrus peel after harvest. However, a high concentration of cinnamaldehyde-chitosan coating $(1.5 \% \mathrm{CI}-\mathrm{CH})$ did affect the normal color change of the citrus peel, and made the CCI value of $1.5 \% \mathrm{CI}-\mathrm{CH}$ fruit significantly lower than that of the control at the end of storage $(p<0.05)$. This may be due to the phytotoxic effect of an excessive concentration of cinnamaldehyde in $1.5 \% \mathrm{CI}-\mathrm{CH}$ [44].

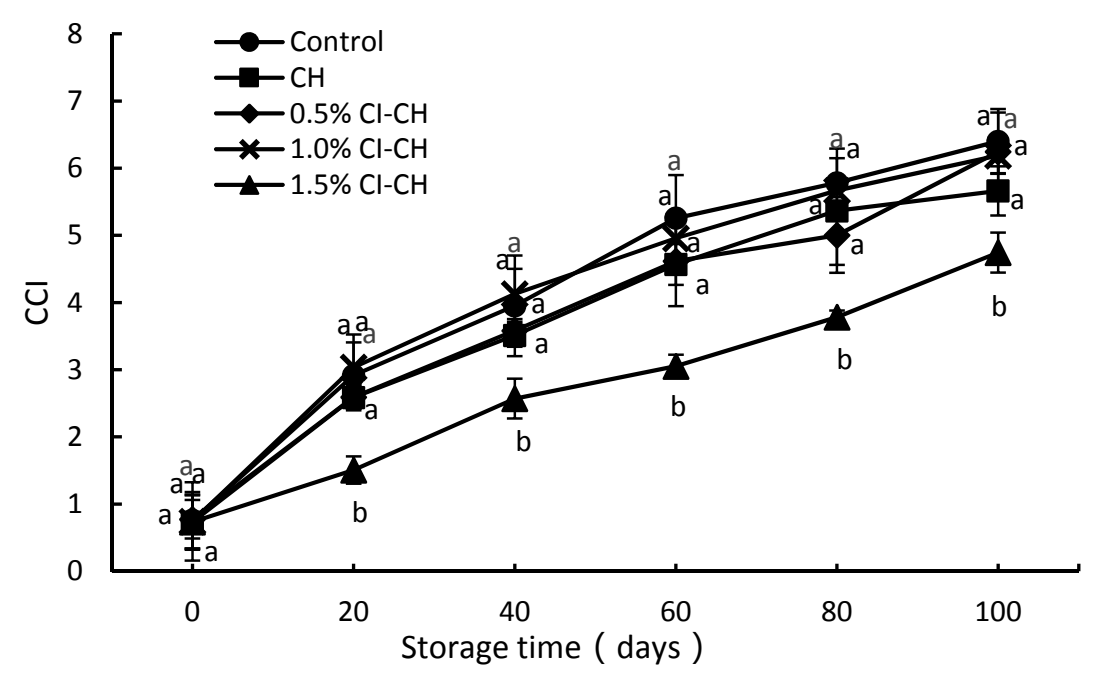

Figure 4. Effect of cinnamaldehyde composite coating on the color composition index (CCI) of mandarin fruits cv. Ponkan during room-temperature storage. Each value represents the mean \pm SD of three replicates; those marked with different lowercase letters are significantly different at $p \leq 0.05$ according to Duncan's multiple range test.

\subsection{Malondialdehyde}

During storage at room temperature, the MDA content of Ponkan fruit gradually increased (Figure 5). This was because the fruit gradually aged as the storage time went on, and the degree of membrane lipid oxidation of the fruit increased. The MDA contents of $\mathrm{CH}, 0.5 \% \mathrm{CI}-\mathrm{CH}$, and $1.0 \%$ $\mathrm{CI}-\mathrm{CH}$ were significantly lower than that of the control fruit $(p<0.05)$. On day 100 of storage, the MDA contents of $\mathrm{CH}$ and $0.5 \%$ and $1.0 \% \mathrm{CI}-\mathrm{CH}$ fruits were $79.71 \%, 62.00 \%$, and $58.60 \%$, respectively, of that of the control fruits $\left(3.00 \mathrm{mmol} \cdot \mathrm{g}^{-1}\right)$. This was because the chitosan and low-concentration cinnamaldehyde coating delayed the senescence of Ponkan fruit during postharvest storage, reduced membrane lipid peroxidation, and hence reduced the MDA content. Hong and colleagues [39] also showed that treatment with $2.0 \%$ chitosan coating delayed the changes of MDA content in Pearl guava fruit during cold storage and induced a significant increase in resistant enzyme activity. However, the MDA content of $1.5 \% \mathrm{CI}-\mathrm{CH}$ fruits increased sharply in the early storage period, and was significantly higher than that of other treated fruits in the late storage period (Figure 5). This could be due to the higher concentration of cinnamaldehyde in the coating treatment, which can damage the epidermal cells of the fruit, increase the permeability of the cell membranes, and rapidly accumulate MDA content [45]. 


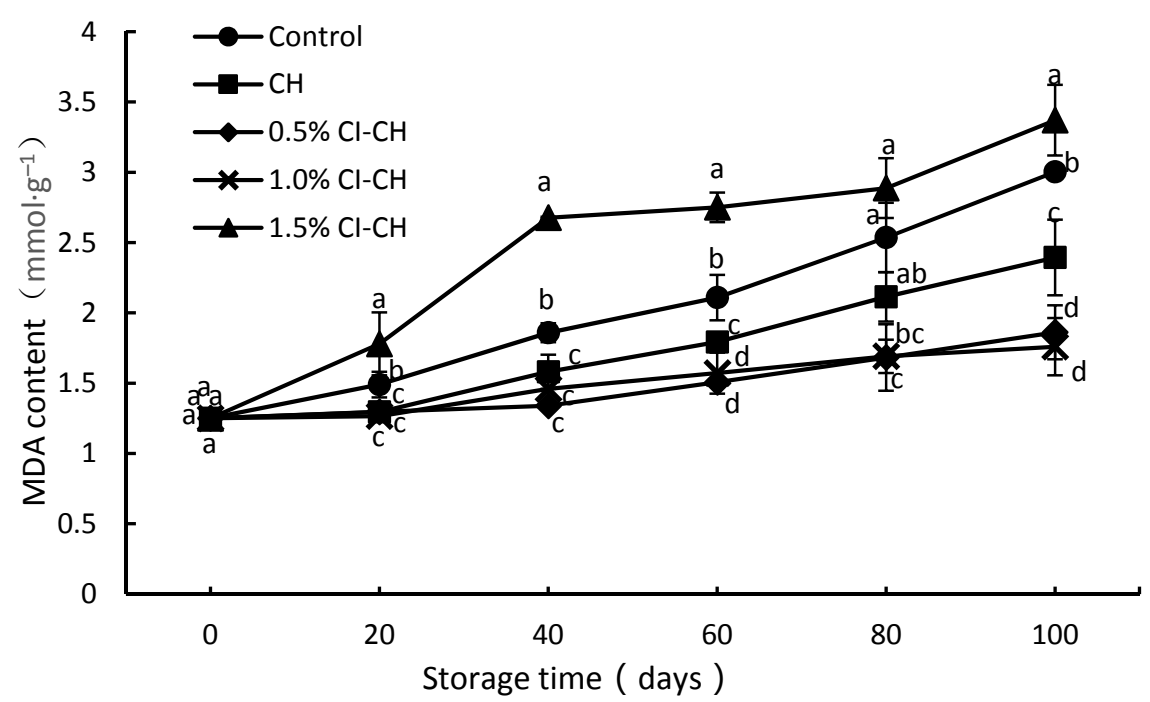

Figure 5. Effect of cinnamaldehyde composite coating on the malondialdehyde (MDA) content of mandarin fruits cv. Ponkan during room-temperature storage. Each value represents the mean $\pm \mathrm{SD}$ of three replicates; those marked with different lowercase letters are significantly different at $p \leq 0.05$ according to Duncan's multiple range test.

\subsection{Activities of Catalase, Peroxidase, and Superoxide Dismutase}

In response to stress, plants normally increase the activity of catalase, peroxidase, and superoxide dismutase. Moreover, a decrease in enzymatic potential may be associated with a reduction in the capacity to prevent damage [26].

The change of CAT activity of Ponkan fruits during storage at room temperature was determined (Figure 6a), and the activity of the control fruit, which decreased slowly in the early storage period and reached the maximum (37.6\%) at 60 days of storage, was higher than the initial value $(0.27 \mathrm{U} / \mathrm{g}$ $\mathrm{min})$. Compared with the control fruit, the CAT activity of $\mathrm{CH}$-treated fruits decreased significantly in the late storage period and was significantly higher than its counterpart control at 100 days of storage $(p<0.05)$. This was similar in the case of the study of the effect of calcium chloride, chitosan, and pullulan coatings on the antioxidant activity of Huangguan pears during storage. Chitosan coating treatment slowed the accumulation of total phenolic and flavonoid content, chlorogenic acid, arbutin, catechin, and caffeic acid, and reduced SOD and CAT activity as well as total antioxidant activity in pear fruits during storage [46]. The CAT activity in $0.5 \%$ and $1.0 \%$ CI-CH fruit significantly increased in the early storage period, and remained at a higher level during subsequent storage. The CAT activity of $0.5 \%$ and $1.0 \% \mathrm{CI}-\mathrm{CH}$ was significantly higher compared to that of the control and $\mathrm{CH}$ fruits at the end of storage $(p<0.05)$. This was due to the low concentration of cinnamaldehyde, which increased the antioxidant enzyme activity in the fruits during storage [15].

The changes of POD and SOD activities of Ponkan fruit were basically the same during storage at room temperature- they increased initially and later decreased (Figure $6 \mathrm{~b}, \mathrm{c}$ ). The POD and SOD activities of control, $\mathrm{CH}$, and $1.5 \% \mathrm{CI}-\mathrm{CH}$ fruits peaked at day 40 of storage. The $0.5 \%$ and $1.0 \%$ CI-CH treatments were able to delay the highest peaks of POD and SOD activities, which peaked at 60 days of storage. The maximum values of POD and SOD activities of $\mathrm{CH}$ and $0.5 \%$ and $1.0 \%$ $\mathrm{CI}-\mathrm{CH}$ fruits were significantly higher than those of the control $(p<0.05)$. The coating treatment significantly delayed the decrease of POD and SOD activities in Ponkan fruit during storage, which made the POD and SOD activities of $\mathrm{CH}$ and $0.5 \%$ and $1.0 \% \mathrm{CI}-\mathrm{CH}$ fruits significantly higher than those of the control $(p<0.05)$. On day 100 of storage, the POD and SOD activities of the control fruits were $48.05 \mathrm{u} / \mathrm{g} \cdot \mathrm{min}$ and $13.39 \mathrm{u} / \mathrm{g} \mathrm{FW}$, respectively. In the fruits treated with $\mathrm{CH}$ and $0.5 \%$ and $1.0 \%$ $\mathrm{CI}-\mathrm{CH}$, the POD activity was $3.57,4.83$, and 4.47 times that of the control, while the SOD activity was $1.65,2.54$, and 2.74 times that of the control, respectively. The chitosan coating lessened the aging 
of fruit during storage, and the antiaging ability of the fruit was enhanced by adding the antifungal component cinnamaldehyde to the chitosan coating. Consistent with Xing and co-workers [23], we found that the chitosan-cinnamaldehyde coating could maintain a high level of antioxidant activity of enzymes such as SOD and POD in sweet pepper preserved for 35 days.
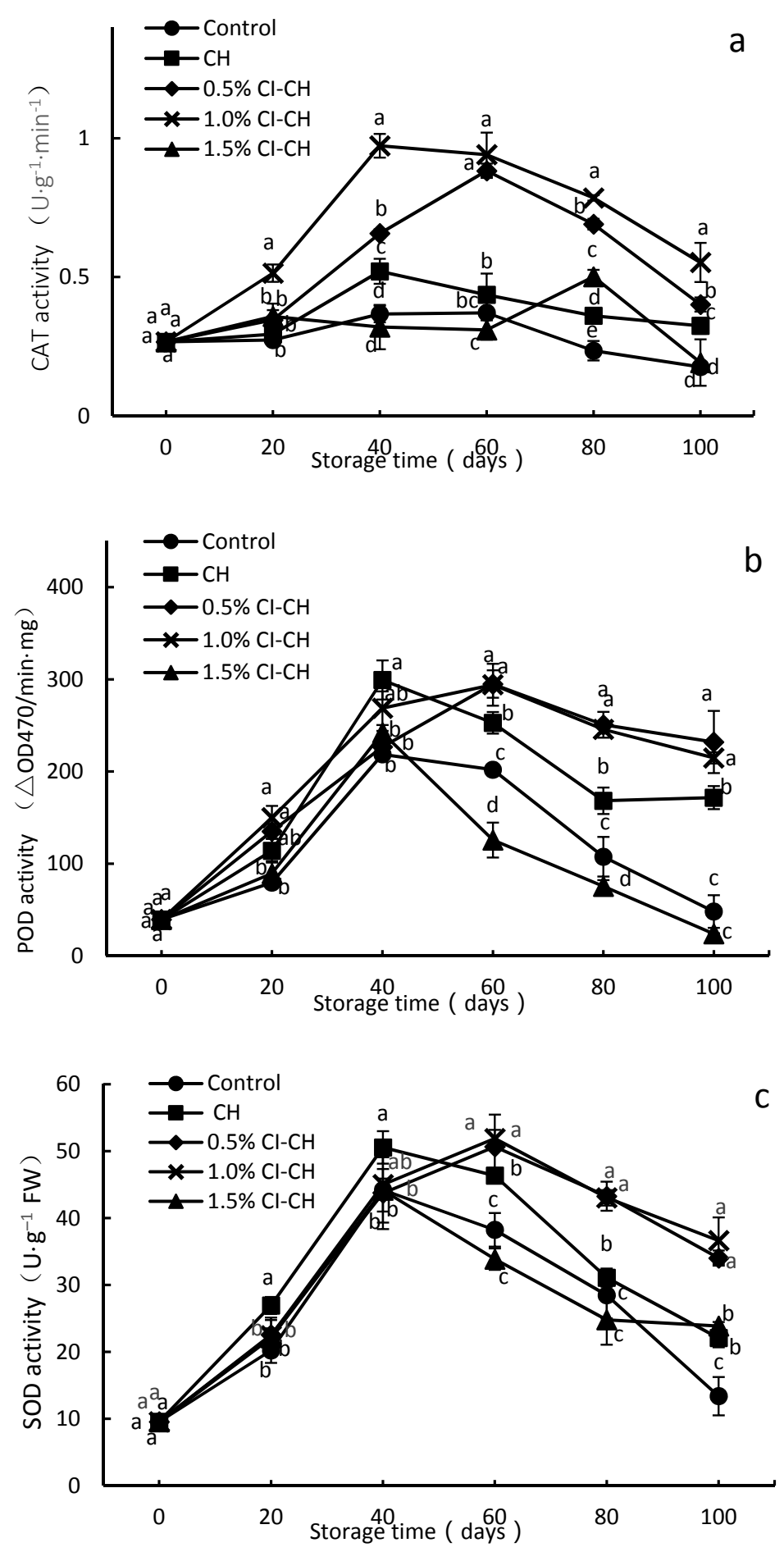

Figure 6. Effect of cinnamaldehyde composite coating on activities of (a) CAT, (b) POD, and (c) SOD in mandarin fruits cv. Ponkan during room-temperature storage. Each value represents the mean $\pm \mathrm{SD}$ of three replicates; those marked with different lowercase letters are significantly different at $p \leq 0.05$ according to Duncan's multiple range test. 


\section{Conclusions}

In this study, a chitosan-cinnamaldehyde composite coating was used to treat citrus fruits before room-temperature storage. The results show that the $1.5 \%$ cinnamaldehyde composite coating inhibited the color change of citrus peel and promoted the accumulation of MDA content, which was not suitable as a preservation for mandarins stored at room temperature. However, $0.5 \%$ and $1.0 \%$ cinnamaldehyde-chitosan coatings had better preservation effects on citrus without affecting the color change of the fruit. They not only reduced the fruit's decay rate, weight loss rate, respiratory intensity, and MDA content, but also reduced the loss of TSS, TA, and Vc, and effectively delayed the activity of CAT, POD, and SOD. The low-concentration cinnamaldehyde-chitosan composite coating film has good application prospects in the preservation and storage of Ponkan fruit to avoid great yield losses.

Author Contributions: Conceptualization, Y.G., M.C. and J.C.; Data curation, Y.G., C.K. and C.W.; Investigation, Y.G., C.K. and M.C.; Methodology, C.K., C.C., Y.C. and Y.F.; Project administration, M.C. and C.C.; Resources, J.C.; Supervision, J.C.; Writing-Original Draft Preparation, Y.G., C.K. and C.W.; Writing-Review \& Editing, Y.G., C.W. and J.C.

Funding: The authors gratefully acknowledge financial support of this study by the National Natural Science Foundation of China (Nos. 31460533 and 31760598), the Natural Science Foundation of Jiangxi Province (No. 20161BAB214167), and the Special Fund Project of Graduate Student Innovation of Jiangxi Province (No. YC2017-B034).

Acknowledgments: We thank Muhammad Farrukh Nisar (Interdisciplinary Research Center in Biomedical Materials, COMSATS Institute of Information Technology, Pakistan) for his linguistic assistance during the preparation of this manuscript.

Conflicts of Interest: The authors declare no conflict of interest.

\section{References}

1. Roongruangsri, W.; Rattanapanone, N.; Leksawasdi, N.; Boonyakiat, D. Changes in organic acid contents and related metabolic enzyme activities at different stages of growth of two tangerine cultivars. J. Agric. Sci. 2012, 4, 276-284. [CrossRef]

2. Tang, D.; Lin, Q.; Lin, J.; Wang, D.; Liu, C.; Wu, W.; Sun, C.; Chen, K. Effects of combined heat and preservative treatment on storability of Ponkan fruit (Citrus reticulata Blanco cv. Ponkan) during postharvest storage. J. Food Qual. 2017, 2017, 5871756. [CrossRef]

3. Yun, Z.; Gao, H.; Ping, L.; Liu, S.; Tao, L.; Shuai, J.; Qiang, X.; Xu, J.; Cheng, Y.; Deng, X. Comparative proteomic and metabolomic profiling of citrus fruit with enhancement of disease resistance by postharvest heat treatment. BMC. Plant Biol. 2013, 13, 44. [CrossRef] [PubMed]

4. Yuan, R. Effects of temperature on fruit thinning with ethephon in 'Golden Delicious' apples. Sci. Hortic. 2007, 113, 8-12. [CrossRef]

5. Rab, A.; Sajid, M.; Bibi, F.; Jan, I.; Nabi, G.; Nawab, K. Quality changes in heat treated sweet orange fruit during storage at low temperature. J. Anim. Plant Sci. 2015, 25, 661-668.

6. Talibi, I.; Boubaker, H.; Boudyach, E.H.; Ait, B.A.A. Alternative methods for the control of postharvest citrus diseases. J. Appl. Microbiol. 2014, 117, 1-17. [CrossRef] [PubMed]

7. Youssef, K.; Ligorio, A.; Nigro, F.; Ippolito, A. Activity of salts incorporated in wax in controlling postharvest diseases of citrus fruit. Postharvest Biol. Technol. 2012, 65, 39-43. [CrossRef]

8. Palou, L.; Valencia-Chamorro, S.; Pérez-Gago, M. Antifungal edible coatings for fresh citrus fruit: A review. Coatings 2015, 5, 962-986. [CrossRef]

9. Tunc, S.; Chollet, E.; Chalier, P.; Preziosi-Belloy, L.; Gontard, N. Combined effect of volatile antimicrobial agents on the growth of Penicillium notatum. Int. J. Mol. Sci. 2007, 113, 263-270. [CrossRef] [PubMed]

10. Bullerman, L.B.; Lieu, F.Y.; Seier, S.A. Inhibition of growth and aflatoxin production by cinnamon and clove oils. Cinnamic aldehyde and eugenol. J. Food Sci. 1977, 42, 1107-1109. [CrossRef]

11. Unlu, M.; Ergene, E.; Unlu, G.V.; Zeytinoglu, H.S.; Vural, N. Composition, antimicrobial activity and in vitro cytotoxicity of essential oil from Cinnamomum zeylanicum Blume (lauraceae). Food Chem. Toxicol. 2010, 48, 3274-3280. [CrossRef] [PubMed] 
12. Wan, C.; Li, P.; Chen, C.; Peng, X.; Li, M.; Chen, M.; Wang, J.; Chen, J. Antifungal activity of Ramulus cinnamomi explored by ${ }^{1} \mathrm{H}-\mathrm{NMR}$ based metabolomics approach. Molecules 2017, 22, 2237. [CrossRef] [PubMed]

13. Chen, Y.H.; Wan, C.P.; Peng, X.; Chen, J.Y. Study on the antifungal mechanisms of the main active ingredients of Ramulus cinnamomi against Penicillium italicum. Modern Food Sci. Technol. 2016, 32, 45-51, 65.

14. Shao, X.; Cao, B.; Xu, F.; Xie, S.; Yu, D.; Wang, H. Effect of postharvest application of chitosan combined with clove oil against citrus green mold. Postharvest Biol. Technol. 2015, 99, 37-43. [CrossRef]

15. Duan, X.; Ouyang, Q.; Tao, N. Effect of applying cinnamaldehyde incorporated in wax on green mould decay in citrus fruits. J. Sci. Food Agric. 2018, 98, 527-533. [CrossRef] [PubMed]

16. Wu, Y.; Duan, X.; Jing, G.; Ouyang, Q.; Tao, N. Cinnamaldehyde inhibits the mycelial growth of Geotrichum citri-aurantii and induces defense responses against sour rot in citrus fruit. Postharvest Biol. Technol. 2017, 129, 23-28. [CrossRef]

17. Ali, A.; Mahmud Tengku, M.M.; Sijam, K.; Siddiqui, Y. Effect of chitosan coatings on the physicochemical characteristics of Eksotika II papaya (Carica papaya L.) fruit during cold storage. Food Chem. 2010, 124, 620-626. [CrossRef]

18. Dutta, P.K.; Shipra, T.; Mehrotra, G.K.; Joydeep, D. Perspectives for chitosan based antimicrobial films in food applications. Food Chem. 2009, 114, 1173-1182. [CrossRef]

19. Liu, Y.; Wang, S.; Lan, W.; Qin, W. Fabrication and testing of pva/chitosan bilayer films for strawberry packaging. Coatings 2017, 7, 109. [CrossRef]

20. Egusa, M.; Iwamoto, R.; Izawa, H.; Morimoto, M.; Saimoto, H.; Kaminaka, H.; Ifuku, S. Characterization of chitosan nanofiber sheets for antifungal application. Int. J. Mol. Sci. 2015, 16, 26202-26210. [CrossRef] [PubMed]

21. Xing, Y.; Xu, Q.; Li, X.; Chen, C.; Ma, L.; Li, S.; Che, Z.; Lin, H. Chitosan-based coating with antimicrobial agents: Preparation, property, mechanism, and application effectiveness on fruits and vegetables. Int. J. Polym. Sci. 2016, 2016. [CrossRef]

22. Fortunati, E.; Giovanale, G.; Luzi, F.; Mazzaglia, A.; Kenny, J.; Torre, L.; Balestra, G. Effective postharvest preservation of kiwifruit and romaine lettuce with a chitosan hydrochloride coating. Coatings 2017, 7, 196. [CrossRef]

23. Xing, Y.; Li, X.; Xu, Q.; Yun, J.; Lu, Y.; Tang, Y. Effects of chitosan coating enriched with cinnamon oil on qualitative properties of sweet pepper (Capsicum annuum L.). Food Chem. 2011, 124, 1443-1450. [CrossRef]

24. Barrett, D.M.; Beaulieu, J.C.; Shewfelt, R. Color, flavor, texture, and nutritional quality of fresh-cut fruits and vegetables: Desirable levels, instrumental and sensory measurement, and the effects of processing. Crit. Rev. Food Sci. 2010, 50, 369-389. [CrossRef] [PubMed]

25. Draper, H.H.; Hadley, M. Malondialdehyde determination as index of lipid peroxidation. Methods Enzymol. $1989,186,421$.

26. Lo'ay, A.A.; Taher, M.A. Effectiveness salicylic acid blending in chitosan/pvp biopolymer coating on antioxidant enzyme activities under low storage temperature stress of 'Banati' guava fruit. Sci. Hortic. 2018, 238, 343-349. [CrossRef]

27. Chen, C.; Peng, X.; Zeng, R.; Wan, C.; Chen, M.; Chen, J. Physiological and biochemical responses in cold-stored citrus fruits to carboxymethyl cellulose coating containing ethanol extract of Impatiens balsamina L. Stems. J. Food Process Pres. 2016, 41, e12999. [CrossRef]

28. Chen, M.; Xie, X.; Lin, Q.; Chen, J.; Grierson, D.; Yin, X.; Sun, C.; Chen, K. Differential expression of organic acid degradation-related genes during fruit development of navel oranges (Citrus sinensis) in two habitats. Plant Mol. Biol. Rep. 2013, 31, 1131-1140. [CrossRef]

29. Zhou, J.Y.; Sun, C.D.; Zhang, L.L.; Xiao, D.; Xu, C.J.; Chen, K.S. Preferential accumulation of orange-colored carotenoids in Ponkan (Citrus reticulata) fruit peel following postharvest application of ethylene or ethephon. Sci. Hortic. 2010, 126, 229-235. [CrossRef]

30. Sofo, A.; Dichio, B.; Xiloyannis, C.; Masia, A. Effects of different irradiance levels on some antioxidant enzymes and on malondialdehyde content during rewatering in olive tree. Plant Sci. 2004, 166, 293-302. [CrossRef]

31. Hirai, M.; Ueno, I. Development of citrus fruits: Fruit development and enzymatic changes in juice vesicle tissue. Plant Cell Physiol. 1977, 18, 791-799.

32. Yaman, O.; Bayoindirli, L. Effects of an edible coating and cold storage on shelf-life and quality of cherries. LWT-Food Sci. Technol. 2002, 35, 146-150. [CrossRef] 
33. Gao, Y.; Kan, C.; Wan, C.; Chen, C.; Chen, M.; Chen, J. Quality and biochemical changes of navel orange fruits during storage as affected by cinnamaldehyde-chitosan coating. Sci. Hortic. 2018, 239, 80-86. [CrossRef]

34. Petriccione, M.; Sanctis, F.D.; Pasquariello, M.S.; Mastrobuoni, F.; Rega, P.; Scortichini, M.; Mencarelli, F. The effect of chitosan coating on the quality and nutraceutical traits of sweet cherry during postharvest life. Food Bioprocess. Technol. 2015, 8, 394-408. [CrossRef]

35. Deng, L.; Zeng, K.; Zhou, Y.; Huang, Y. Effects of postharvest oligochitosan treatment on anthracnose disease in citrus (Citrus sinensis L. Osbeck) fruit. Eur. Food Res. Technol. 2015, 240, 795-804. [CrossRef]

36. Marin, L.; Ailincai, D.; Mares, M.; Paslaru, E.; Cristea, M.; Nica, V.; Simionescu, B.C. Imino-chitosan biopolymeric films. Obtaining, self-assembling, surface and antimicrobial properties. Carbohydr. Polym. 2015, 117, 762-770. [CrossRef] [PubMed]

37. Marin, L.; Moraru, S.; Popescu, M.C.; Nicolescu, A.; Zgardan, C.; Simionescu, B.C.; Barboiu, M. Out-of-water constitutional self-organization of chitosan-cinnamaldehyde dynagels. Chem. Eur. J. 2014, 20, 4814-4821. [CrossRef] [PubMed]

38. Chen, H.; Hu, X.; Chen, E.; Wu, S.; Mcclements, D.J.; Liu, S.; Li, B.; Li, Y. Preparation, characterization, and properties of chitosan films with cinnamaldehyde nanoemulsions. Food Hydrocolloids 2016, 61, 662-671. [CrossRef]

39. Hong, K.; Xie, J.; Zhang, L.; Sun, D.; Gong, D. Effects of chitosan coating on postharvest life and quality of guava (Psidium guajava L.) fruit during cold storage. Sci. Hortic. 2012, 144, 172-178. [CrossRef]

40. Ling, S.; Shen, D.; Yi, L.; Sun, X.; Wang, J.; Tao, L.; Zeng, Y.; Xu, J.; Deng, X.; Cheng, Y. Exogenous $\gamma$-aminobutyric acid treatment affects citrate and amino acid accumulation to improve fruit quality and storage performance of postharvest citrus fruit. Food Chem. 2017, 216, 138-145.

41. Chen, C.; Peng, X.; Zeng, R.; Chen, M.; Wan, C.; Chen, J. Ficus hirta fruits extract incorporated into an alginate-based edible coating for Nanfeng mandarin preservation. Sci. Hortic. 2016, 202, 41-48. [CrossRef]

42. Kou, X.H.; Wang, S.; Zhang, Y.; Guo, R.Z.; Wu, M.S.; Chen, Q.; Xue, Z.H. Effects of chitosan and calcium chloride treatments on malic acid-metabolizing enzymes and the related gene expression in post-harvest pear cv. 'Huang guan'. Sci. Hortic. 2014, 165, 252-259. [CrossRef]

43. Peng, G.; Xie, X.L.; Jiang, Q.; Song, S.; Xu, C.J. Chlorophyll a/b binding protein plays a key role in natural and ethylene-induced degreening of Ponkan (Citrus reticulata Blanco). Sci. Hortic. 2013, 160, 37-43. [CrossRef]

44. Murmu, S.B.; Mishra, H.N. The effect of edible coating based on Arabic gum, sodium caseinate and essential oil of cinnamon and lemon grass on guava. Food Chem. 2018, 245, 820-828. [CrossRef] [PubMed]

45. Yan, H.K.; Zhu, H.Y.; Cao, M.J.; Zhang, J.J.; Wang, X.G.; Chen, Y.J. Relation between leaf mda content and protection system of low potassium tolerant maize inbred lines under different potassium concentration. J. Jilin Agric. Univ. 2010, 32, 5-8.

46. Kou, X.H.; Guo, W.L.; Guo, R.Z.; Li, X.Y.; Xue, Z.H. Effects of chitosan, calcium chloride, and pullulan coating treatments on antioxidant activity in pear cv. "Huang guan" during storage. Food Bioprocess Technol. 2014, 7, 671-681. [CrossRef]

(C) 2018 by the authors. Licensee MDPI, Basel, Switzerland. This article is an open access article distributed under the terms and conditions of the Creative Commons Attribution (CC BY) license (http:// creativecommons.org/licenses/by/4.0/). 